\title{
Coronary artery bypass grafts to chronic occluded right coronary arteries
}

Maleen Fiddicke, Cand Med, ${ }^{\mathrm{a}}$ Felix Fleissner, MD, ${ }^{\mathrm{a}}$ Tonita Brunkhorst, Cand Med, ${ }^{\mathrm{a}}$

Eva M. Kühn, Cand Med, ${ }^{\mathrm{a}}$ Doha Obed, MD, ${ }^{\mathrm{b}}$ Dietmar Boethig, MD, ${ }^{\mathrm{a}}$ Issam Ismail, MD, ${ }^{\mathrm{a}}$

Axel Haverich, MD, ${ }^{a}$ Gregor Warnecke, $M D,{ }^{c}$ and Wiebke Sommer, $\mathrm{MD}^{\mathrm{c}}$

\section{ABSTRACT}

Background: The benefit of revascularizing chronically occluded coronary arteries remains debatable, and available long-term outcome reports are sparse. Current guidelines recommend revascularization of chronically occluded arteries only in patients with myocardial ischemia and/or symptoms associated with angina. We investigated outcome of patients with total chronic occlusion of the right coronary artery ( $R C A$ ) receiving coronary artery bypass grafting ( $C A B G)$ surgery with and without revascularization of the RCA.

Methods: We retrospectively analyzed all patients with chronically occluded RCAs receiving $C A B G$ with (group $1=R C A-C A B G ; n=487$ ) and without (group $2=$ No$\mathrm{RCA}-\mathrm{CABG} ; \mathrm{n}=100$ ) revascularization of the $\mathrm{RCA}$. In total, 587 patients with complete follow-up of a minimum of 6 years were included $(92 \%)$.

Results: In total, $82 \%$ in group 1 versus $86 \%$ in group 2 were male $(P=.38)$. European System for Cardiac Operative Risk Evaluation II was comparable between both groups ( $4.35 \pm 7.09 \%$ vs $4.80 \pm 5.77 \%, P=.56)$ with no major differences regarding preoperative characteristics between groups. Patients in group 1 received $3.24 \pm 0.79$ distal anastomoses, whereas group 2 received $2.45 \pm 0.83$ distal anastomoses $(P<.001)$. Although in-hospital mortality was comparable $(2.9 \%$ in group 1 vs $5.0 \%$ in group $2, P=.27$ ), long-term survival was significantly better in group 1 $(P=.002)$. No difference in the incidence of further major adverse cardiac and cerebrovascular events was found.

Conclusions: Patients with a chronically occluded RCA undergoing CABG who did not receive an RCA graft showed a significantly reduced long-term survival. Given the herein presented data, revascularization of chronically occluded right arteries during CABG should be recommended whenever technically feasible. (JTCVS Open 2021;7:169-79)

Coronary artery disease (CAD) and its ideal treatment are increasingly challenging since patients' morbidity and the complexity of comorbidities are increasing. Several studies have been conducted showing that patients with multivessel

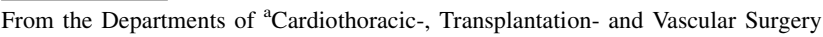
and ${ }^{b}$ Plastic- and Reconstructive Surgery, Hannover Medical School, Hannover; and ${ }^{c}$ Department of Cardiac Surgery, University of Heidelberg, Heidelberg, Germany.

Ms Fiddicke and Drs Fleissner, Warnecke, and Sommer contributed equally to this article.

Received for publication Jan 5, 2021; accepted for publication June 4, 2021; available ahead of print June 27, 2021.

Address for reprints: Wiebke Sommer, MD, Department of Cardiac Surgery, University of Heidelberg, Im Neuenheimer Feld 420, 69120 Heidelberg, Germany (E-mail: wiebke.sommer@med.uni-heidelberg.de).

2666-2736

Copyright (C) 2021 The Author(s). Published by Elsevier Inc. on behalf of The American Association for Thoracic Surgery. This is an open access article under the CC BY-NC-ND license (http://creativecommons.org/licenses/by-nc-nd/4.0/).

https://doi.org/10.1016/j.xjon.2021.06.007
}

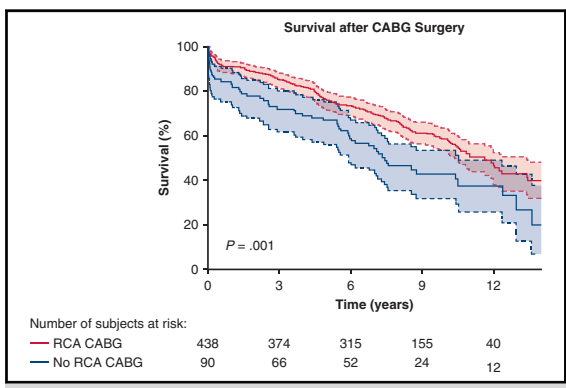

Survival in patients with CTO RCA is superior when receiving CABG to the RCA.

\section{CENTRAL MESSAGE}

Revascularization of chronically occluded right coronary arteries improves overall survival.

\section{PERSPECTIVE}

There is no clear evidence whether CTO coronary arteries should be revascularized during CABG surgery. In this analysis, overall survival was significantly better in patients who received a CABG to the CTO RCA as compared with patients who did not receive a CABG to the CTO RCA. No difference in incidence of MACCE was detectable. Therefore, CABG of CTO RCA is recommended.

\section{See Commentary on page 180.}

CAD have a long-term survival benefit and suffer less from major adverse cardiac and cerebrovascular events (MACCE) when undergoing complete revascularization (CR) as compared with incomplete revascularization (IR). ${ }^{1,2}$ Nevertheless, patients with chronic total occlusion (CTO)_defined as a $100 \%$ stenosis in a coronary artery for $\geq 3$ months - are less likely to receive CR, especially when CTO is located in the right coronary artery (RCA). ${ }^{3-6} \mathrm{CTO}$ is a common finding in coronary angiograms of patients with CAD. The reported prevalence varies from $18 \%{ }^{5}$ to $49 \%{ }^{7}$ with the RCA being most frequently affected $(47 \%-51 \%){ }^{4,5,8}$ Although CR is known to lead to a survival benefit in multivessel CAD, ${ }^{2}$ $\mathrm{CR}$ is not routinely performed in CTO vessels ${ }^{5}$ due to severe arteriosclerosis, narrow diameters, ${ }^{3,9}$ and greater incidence of saphenous bypass failure in CTO vessels. ${ }^{10}$ These aspects may also contribute to a greater incidence of MACCE 


\section{Abbreviations and Acronyms \\ $\mathrm{CABG}=$ coronary artery bypass grafting \\ $\mathrm{CAD}=$ coronary artery disease \\ $\mathrm{CR}=$ complete revascularization \\ CTO $=$ chronic total occlusion \\ EuroSCORE II = European System for Cardiac \\ Operative Risk Evaluation II \\ IQR $=$ interquartile range \\ IR $\quad$ incomplete revascularization \\ MACCE $=$ major adverse cardiac and cerebrovascular events
MI $=$ myocardial infarction
PCI $=$ percutaneous coronary intervention
RCA = right coronary artery

in patients with CTO-RCA as compared with patients with non-CTO-RCA. ${ }^{3}$

Since chronic occlusion of the RCA is often not correlated to clinical symptoms of patients, clear treatment strategies are not included in current guidelines. Hence, the aim of this study is to examine whether revascularization of chronically occluded RCAs and its associated vessels leads to a clinical benefit, thus providing a recommendation whether CTO-RCA should generally undergo revascularization.

\section{PATIENTS AND METHODS}

This study has been conducted as a single-center, retrospective observational study (case control study). Retrospective data collection from 2002 to 2011 was approved by the institutional review board of Hannover Medical School (024-04-2018, date: April 9, 2018).

\section{Inclusion Criteria}

Patients undergoing coronary artery bypass grafting (CABG) at Hannover Medical School with the preoperative diagnosis of chronic occluded RCA were included into the study. Chronic occlusion of the RCA was defined as $100 \%$ stenosis in the main branch of the RCA without antegrade flow (Thrombolysis in Myocardial Infarction = TIMI 0), which was assumed to exist for $\geq 3$ months or presented with visible collateralization to the distal branches. Diagnoses were acquired by coronary angiography.

Patients were included with a minimum follow-up of 6 years after CABG surgery, and patients or primary care physicians were contacted either by telephone or by letter for further follow-up. Patients with a shorter follow-up were not included into the analysis. Informed consent was obtained from all patients for data use, including postoperative angiograms and medical reports.

The following groups were compared in regard to preoperative baseline characteristics, perioperative characteristics, as well as postoperative MACCE and survival:

Group $1=$ RCA bypass: patients with CTO-RCA who received at least 1 bypass in the myocardial area supplied by the RCA or its major branches (posterior descending artery, right posterolateral artery).

Group 2 = No RCA bypass: patients with CTO-RCA who did not receive a bypass in the myocardial area supplied by the RCA or its major branches.
In addition, a subgroup analysis on patients who solely received CABG surgery without any other surgical procedure was performed, comparing percutaneous coronary intervention (PCI)-free survival, myocardial infarction (MI)-free survival, stroke-free survival, as well as overall survival between patients who received revascularization of a chronically occluded RCA or not.

\section{End Points}

Primary end point was the incidence of all-cause death. Secondary end points were MACCE, defined as coronary reinterventions by either CABG or PCI, the occurrence of postoperative MIs, or strokes.

In addition, standard cardiovascular risk factors were included in the postoperative follow-up. As such, familiar predisposition was defined according to current guidelines: familiar manifestation of atherosclerosis earlier than 55 years in male first-degree relatives or earlier than 65 years in female first-degree relatives, respectively. The definition of "critical preoperative state" was extracted from the European System for Cardiac Operative Risk Evaluation II (EuroSCORE II): ventricular tachycardia or ventricular fibrillation or aborted sudden death, preoperative cardiac massage, preoperative ventilation before the anesthetic room, preoperative inotropes or intra-aortic balloon pump, or preoperative acute renal failure (anuria or oliguria $<10 \mathrm{~mL} / \mathrm{h}$ ). ${ }^{11}$ The expected mortality risk for surgery was calculated using EuroSCORE II.

\section{Statistical Analysis}

All statistical analyses were calculated using IBM SPSS Statistics 21 (IBM Corp, Armonk, NY) or GraphPad Prism 7 (GraphPad Software, San Diego, Calif). Categorial variables were compared with the $\chi^{2}$ test or the Fisher exact test, respectively. To examine which categorial comparison caused significance, post hoc comparisons were conducted. In this case, the $P$ value had to be adapted for the number of comparisons using Bonferroni correction. Metric variables were compared using Student $t$ test for independent samples or Mann-Whitney $U$ test. Homogeneity of variances was analyzed with the Levene test. Survival was compared with Kaplan-Meier survival analysis and log-rank test. 95\% confidence limits are displayed in the respective figures. To examine which variables independently influence the survival benefit, a Cox regression was conducted including the following variables: therapy (RCA-CABG vs No-RCACABG), body mass index, arterial hypertension, atrial fibrillation, carotid stenosis $\geq 50 \%$, familiar predisposition, hyperlipidemia, smoking, preoperative stroke, and EuroSCORE II.

\section{RESULTS}

\section{Preoperative and Perioperative Characteristics}

In both subgroups, median (interquartile range [IQR]) age was $67(60 ; 73)$ versus $67(59 ; 74)$ years $(P=.59)$; $82.3 \%$ in group 1 versus $86 \%$ in group 2 were male $(P=.38)$, respectively. Mean EuroSCORE II was similar in the RCA-CABG group $(4.4 \pm 7.1 \%)$ versus the NoRCA-CABG group $(4.8 \pm 5.8 \% ; P=.20)$.

Regarding further preoperative characteristics, both groups showed no differences, with the exception that patients receiving RCA-CABG more often underwent isolated CABG surgery $\left(\chi^{2}[2]=6.23, P=.04\right)$. However, this significance was not confirmed by post hoc analysis $(P>.008$, Bonferroni correction: $P=.008$ ) (Table 1).

Comparisons of perioperative characteristics did not reveal any differences apart from significantly more right internal mammary artery grafts in the No-RCA-CABG group (Fisher exact test, $P=.001$ ). The difference 


\section{TABLE 1. Baseline preoperative characteristics}

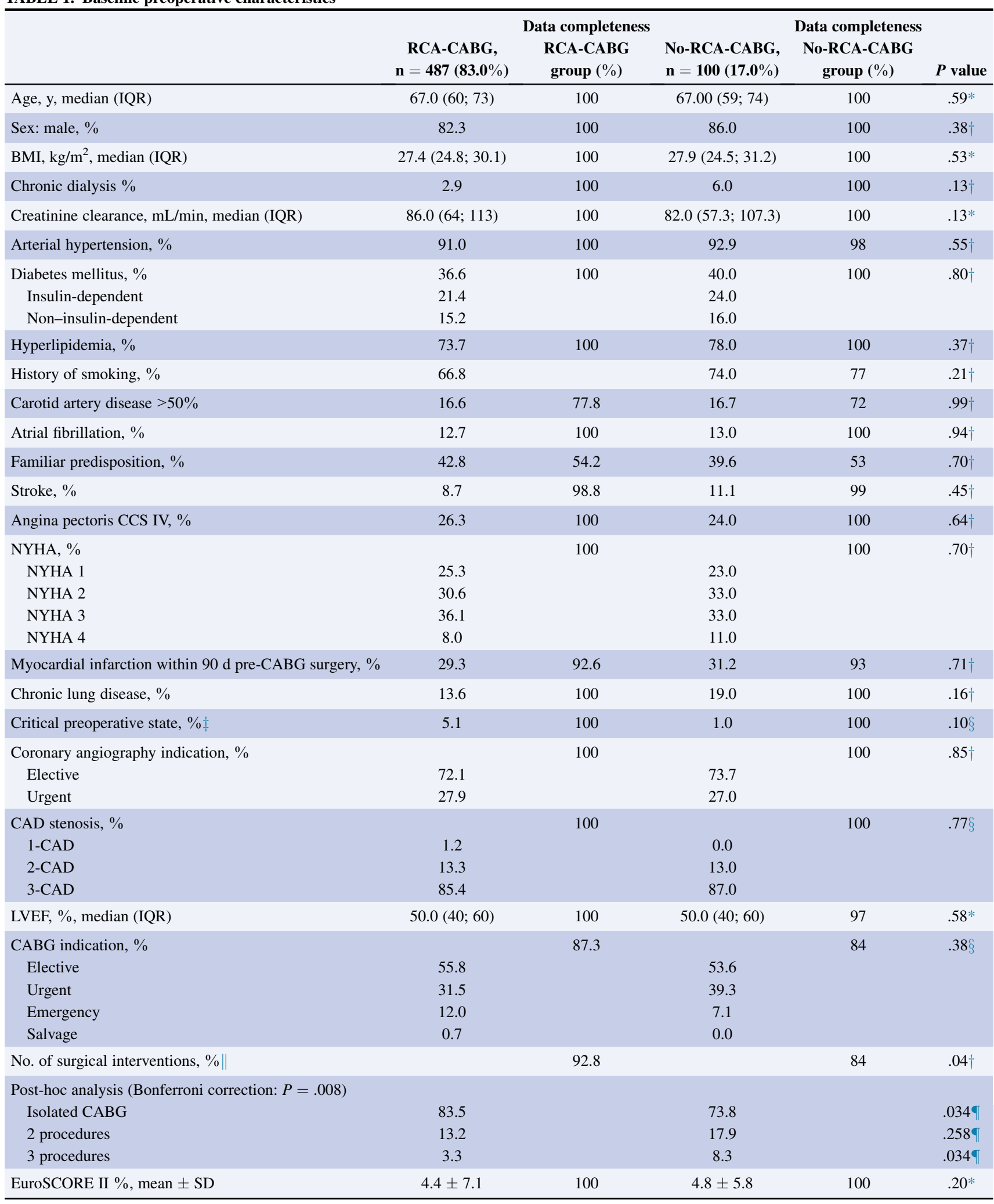

$R C A$, Right coronary artery; $C A B G$, coronary artery bypass graft; $I Q R$, interquartile range; $B M I$, body mass index; $C C S$, Canadian Cardiovascular Society; $N Y H A$, New York Heart Association; $C A D$, coronary artery disease; $L V E F$, left ventricular ejection fraction; EuroSCORE II, European System for Cardiac Operative Risk Evaluation II; SD, stan-

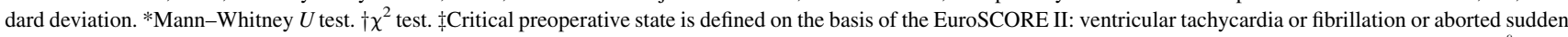
death, preoperative CPR, preoperative ventilation before anesthetic room, preoperative inotropes or IABP, preoperative acute renal failure (anuria or oliguria $<10 \mathrm{~mL} / \mathrm{h}$ ). ${ }^{\S}$ Fisher exact test. \|Procedures are defined by EuroSCORE II as "CABG, valve repair or replacement, repair of a structural defect, maze procedure, resection of a cardiac tumor." $₫$ Posthoc analysis with Bonferroni correction (for 6 comparisons: $P=.008$ ). 
TABLE 2. Perioperative characteristics

\begin{tabular}{|c|c|c|c|}
\hline & RCA-CABG, $n=487(83.0 \%)$ & No-RCA-CABG, $\mathrm{n}=100(17.0 \%)$ & $P$ value \\
\hline Duration of surgery, min, median (IQR) & $196.0(173 ; 225)$ & $183.5(155.8 ; 215)$ & $.02 *$ \\
\hline Duration of cardiopulmonary bypass, min, median (IQR) & $86.0(70 ; 110)$ & $78.5(59 ; 103)$ & $.02 *$ \\
\hline Duration of aortic clamp time, min, median (IQR) & $47.0(37 ; 60)$ & $43.0(27 ; 58)$ & $.01 *$ \\
\hline Off-pump CABG, $n$ & 2 & 1 & $.43 \dagger$ \\
\hline Venous grafts, $\%$ & & & $.04 \dagger$ \\
\hline \multicolumn{4}{|l|}{ Post-hoc analysis (Bonferroni correction: $P=.006$ ) } \\
\hline 0 & 30.6 & 45.0 & $.05 \ddagger$ \\
\hline 1 & 49.9 & 43.0 & $.66 \ddagger$ \\
\hline 2 & 18.7 & 12.0 & $.46 \ddagger$ \\
\hline 3 & 0.8 & 0.0 & $.84 \ddagger$ \\
\hline LIMA grafts, $\%$ & & & $.17 \S$ \\
\hline 0 & 15.4 & 21.0 & \\
\hline 1 & 84.6 & 79.0 & \\
\hline RIMA grafts, $\%$ & & & $.001 \dagger$ \\
\hline 0 & 99.2 & 93.0 & \\
\hline 1 & 0.8 & 7.0 & \\
\hline Radialis grafts, $\%$ & & & $.59 \S$ \\
\hline 0 & 68.8 & 66.0 & \\
\hline 1 & 31.2 & 34.0 & \\
\hline Number of distal anastomoses, median (IQR) & $3(3 ; 4)$ & $2(2 ; 3)$ & $<.001^{*}$ \\
\hline Complete revascularization, $\%$ & 86.5 & 0.0 & $<.001 \dagger$ \\
\hline Postoperative ICU stay, d, median (IQR) & $1(1 ; 3)$ & $1(1 ; 2)$ & $.20^{*}$ \\
\hline Total hospital stay, d, median (IQR) & $13(10 ; 16)$ & $12(9 ; 16)$ & $.10^{*}$ \\
\hline
\end{tabular}

regarding the number of venous grafts in both groups did not remain significant after post-hoc analysis $(P>.006$, Bonferroni correction: $P=.006$ ). Moreover, the number of distal anastomoses was slightly lower in the No-RCACABG group (median [IQR] $2[2 ; 3]$ ) as compared with the RCA-CABG group (median [IQR] $3(3 ; 4)$, T $[585]=-8.997, P<.001)$. Duration of surgery as well as aortic clamp time showed no significant differences between both groups (Table 2). Similarly, duration of cardiopulmonary bypass time was comparable in both groups (Table 2).

In $83.0 \%$ of the patients with a chronically occluded main stem of the RCA, CABG was conducted for the RCA or its consecutive distal branches. In $15.4 \%$, the RCA territory was supplied by grafts anastomosed to the RCA stem, whereas in $77.4 \%$ the ramus interventricularis posterior and in $8.9 \%$ the ramus posterolateralis dexter or right posterolateral artery were anastomosed. The majority of the patients in the RCA-CABG group received 1 graft in the RCA area $(97.1 \%)$, whereas only few received 2 anastomoses $(2.9 \%)$. CR was realized in $86.7 \%$ of the RCA$\mathrm{CABG}$ group. Coronary endarterectomy was performed in 5 patients in the RCA or its larger branches in patients who received CABG revascularization of the RCA, 3 patients underwent endarterectomy in the left coronary arterial system. Information on why a chronically occluded RCA did not undergo revascularization was available in 54 patients. In 53 of these, small vessel size or no suitable site for anastomosis was given as a reason for not grafting the vessel. A bias caused by individual surgeons that might impact the analysis was not identified.

\section{Early Postoperative Outcome}

Apart from significantly fewer cardiopulmonary resuscitations in the RCA-CAGB group ( $1.6 \%$ vs $5.0 \%$ in the NoRCA-CABG group; $\chi^{2}$ test $\left.[1]=4.32, P=.04\right)$, no further differences were detectable in the early postoperative course (Table 3). Overall, in-hospital mortality was $2.9 \%$ $(\mathrm{n}=14)$ for the RCA-CABG group versus $5.0 \%(\mathrm{n}=5)$ for the No-RCA-CABG group $\left(\chi^{2}[1]=1.2, P=.27\right)$, which is consistent with the expected mortality (EuroSCORE II RCA-CABG group 4.35\% [ \pm 7.09$]$ vs the NoRCA-CABG group $4.80 \%[ \pm 5.77])$. Surgical revision of the CABG was necessary in 4 cases-3 times in the RCA-CABG group $(0.6 \%)$ versus once in the No-RCACABG group ( $1.0 \%$, Fisher exact test, $P=1.00)$ (Table 3 ).

Follow-up data showed a significantly superior survival in patients receiving revascularization of a chronically 
TABLE 3. Early postoperative complications

\begin{tabular}{|c|c|c|c|}
\hline & RCA-CABG, $n=487(83.0 \%)$ & No-RCA-CABG, $n=100(17.0 \%)$ & $P$ value \\
\hline Revision CABG, n (\%) & $3(0.6)$ & $1(1.0)$ & $.53^{*}$ \\
\hline Peripheral wound healing disorder, $\mathrm{n}(\%)$ & $10(2.1)$ & $1(1.0)$ & $.70^{*}$ \\
\hline Sternal wound healing disorder, $\mathrm{n}(\%)$ & $16(3.3)$ & $1(1.0)$ & $.33^{*}$ \\
\hline Re-thoracotomy for bleeding, $\mathrm{n}(\%)$ & $17(3.5)$ & $5(5.0)$ & $.47 \dagger$ \\
\hline Myocardial infarction, $\mathrm{n}(\%)$ & $4(0.8)$ & $0(0.0)$ & $1.00 *$ \\
\hline IABP, n (\%) & $19(3.9)$ & $4(4.0)$ & $1.00^{*}$ \\
\hline Cardiopulmonary resuscitation, $\mathrm{n}(\%)$ & $8(1.6)$ & $5(5.0)$ & $.04 \dagger$ \\
\hline Low cardiac output syndrome, $\mathrm{n}(\%)$ & $13(2.7)$ & $1(1.0)$ & $.48^{*}$ \\
\hline Respiratory failure, $\mathrm{n}(\%)$ & $36(7.4)$ & $11(11.0)$ & $.23 \dagger$ \\
\hline Neurologic disorder, $\mathrm{n}(\%)$ & $13(2.7)$ & $3(3.0)$ & $.74 *$ \\
\hline Renal failure, n (\%) & $8(1.6)$ & $1(1.0)$ & $1.00^{*}$ \\
\hline Dialysis, n (\%) & $13(2.7)$ & $2(2.0)$ & $1.00^{*}$ \\
\hline In-hospital mortality, n (\%) & $14(2.9)$ & $5(5.0)$ & $.27 \dagger$ \\
\hline
\end{tabular}

$R C A$, Right coronary artery; $C A B G$, coronary artery bypass grafting; $I A B P$, intra-aortic balloon pump. *Fisher exact test. $\dagger \chi^{2}$ test.

occluded RCA (Figure 1, A). In the long-term follow-up, patients receiving revascularization of the RCA showed a significant better overall survival as compared with patients without RCA revascularization (log-rank, $P=.002$ ) (Figure 2, A).

No significant difference in the incidence of MACCE was detectable in both groups. Primary end points such as coronary re-revascularization by CABG (Fisher exact test, $P=1.00$ ) or PCI (Fisher exact test, $P=.14$ ) (Figure 2, $B)$, postoperative MI (Fisher exact test, $P=.63$ ) (Figure 2, C), or stroke $\left(\chi^{2}[1]=0.94, P=.33\right.$ )
(Figure 2,D) were similarly distributed between both groups (Table 4). In addition, log rank analysis revealed that freedom of MACCE between both cohorts was similar as well (Table 4, Figure 2).

A subgroup analysis focusing on patients that received only $\mathrm{CABG}$ procedures without any additional surgical intervention supported the previous findings, showing no significant differences in PCI-free survival $(P=.30, \log$ rank) (Figure 3, $B)$, MI-free survival $(P=.53, \log$-rank) (Figure 3,C), or stroke-free survival $(P=.27$, log-rank) (Figure 3, D) between both groups. However, the survival

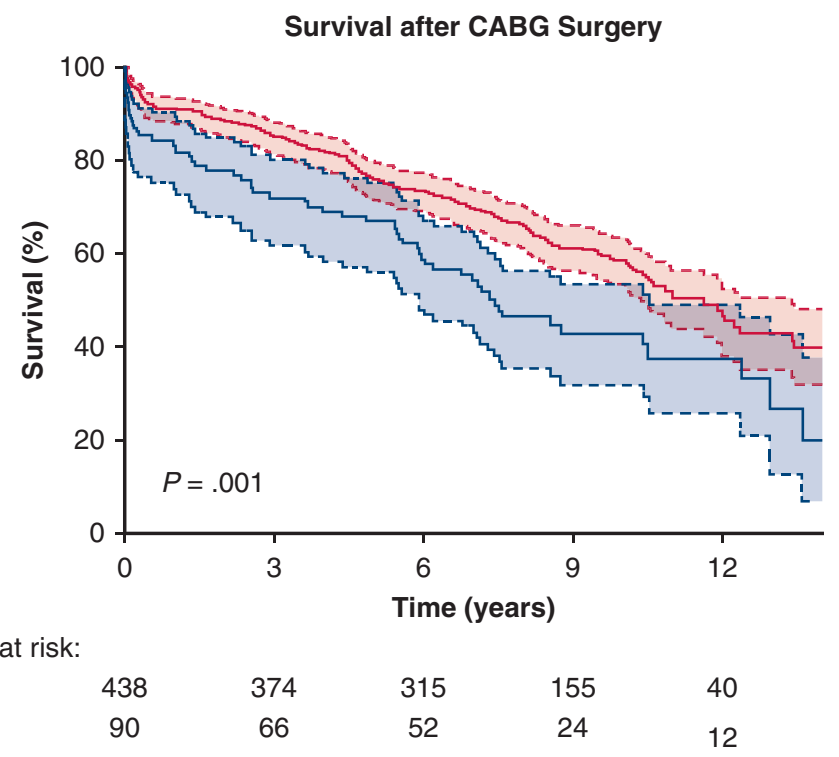

FIGURE 1. Survival analysis after CABG surgery comparing patients who received grafting with the chronically occluded right coronary artery or not. Follow-up comprises a follow-up interval of 14 years with a minimum follow-up of 6 years per patient. Log-rank analysis shows a survival benefit for patients who received coronary bypass grafting to the chronic occluded right coronary artery $(P=.001) .95 \%$ confidence limits are displayed in shadings. $C A B G$, Coronary artery bypass grafting; $R C A$, right coronary artery. 

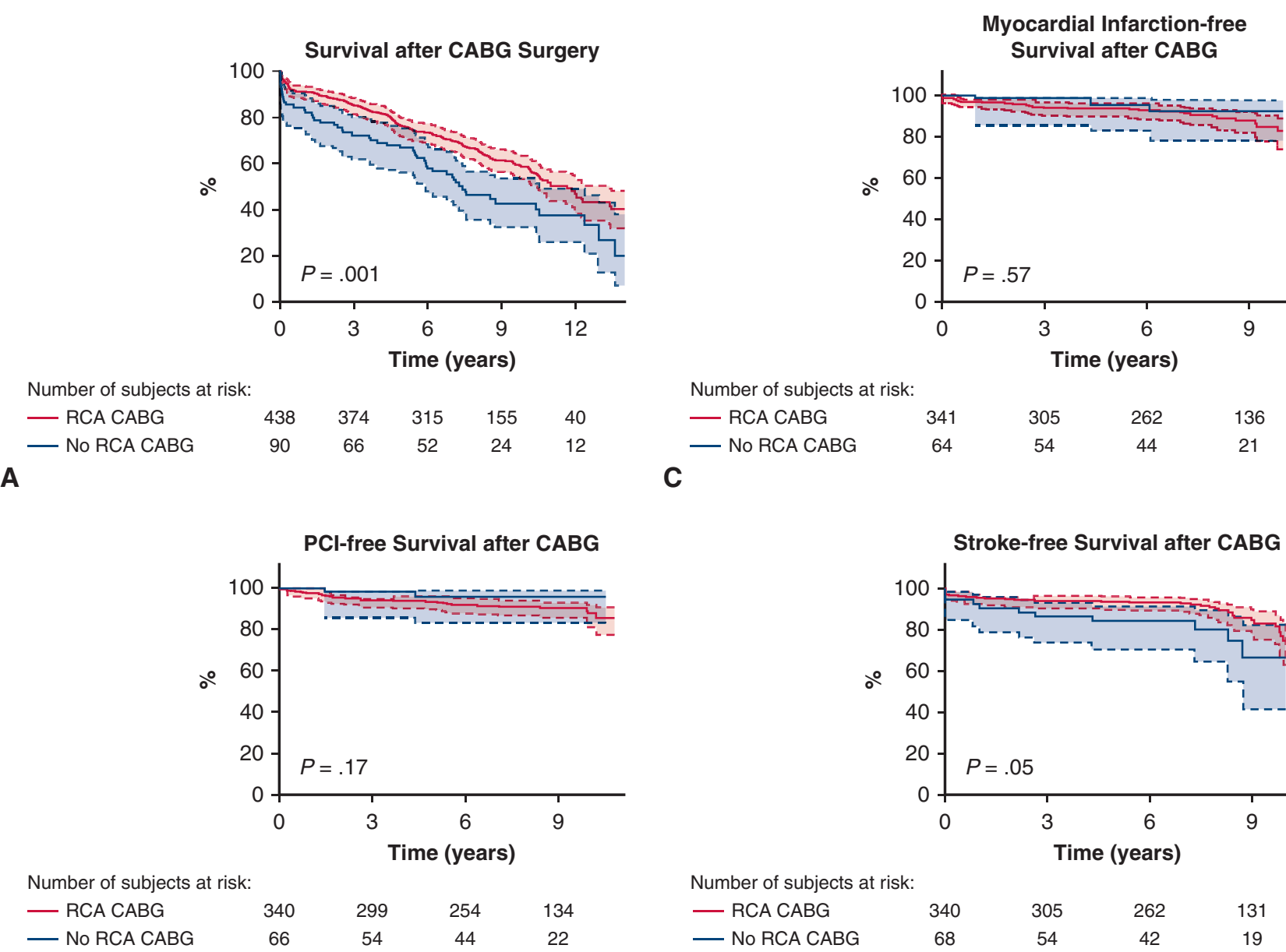

B

$\begin{array}{lcccc}\text { Number of subjects at risk: } & & & & \\ \text { - RCA CABG } & 340 & 299 & 254 & 134 \\ \text { - No RCA CABG } & 66 & 54 & 44 & 22\end{array}$

FIGURE 2. Log-rank analyses with $95 \%$ confidence limits in shadings. A, Survival analysis after CABG surgery comparing patients who received grafting to the chronically occluded RCA or not. Follow-up comprises a follow-up interval of 14 years with a minimum follow-up of 6 years per patient. Log-rank analysis shows a survival benefit for patients that received coronary bypass grafting to the chronic occluded RCA $(P=.001)$; B, PCI-free survival after CABG surgery. Comparison of patients who received CABG grafting to the chronically occluded RCA and patients who did not receive revascularization of the occluded RCA, log-rank analysis shows no significant difference between both groups $(P=.17)$. C, Myocardial infarction-free survival after CABG surgery. Log-rank analysis shows no significant difference in myocardial infarction-free survival after CABG surgery in patients who received revascularization to the chronically occluded RCA and patients who did not receive surgical revascularization to the occluded RCA $(P=.57)$. D, Stroke free survival after CABG surgery. No significant difference is detectable for stroke-free survival in patients receiving CABG grafting to the chronically occluded RCA and patients who did not receive surgical revascularization $(P=.05)$. $C A B G$, Coronary artery bypass grafting; $R C A$, right coronary artery; $P C I$, percutaneous coronary intervention.

benefit of patients receiving surgical revascularization of the chronically occluded RCA was also detectable in this subgroup analysis $(P=.047, \log$-rank) (Figure $3, A)$.

Median follow-up of the RCA CABG group was (median [IQR]) $8.1(5.6 ; 10.2)$ years. Median (IQR) follow-up of the No RCA group was $7.2(3.7 ; 10.3)$ years.

The following significant $(P \leq .05)$ and borderline significant variables $(P \leq .15)$ calculated by a univariate analysis were included in the Cox regression: bypass RCA, EuroSCORE II, preoperative body mass index, atrial fibrillation, familiar predisposition, hyperlipidemia, smoking, and stroke. Cox regression revealed that EuroSCORE
$\mathrm{II}(\operatorname{Exp}[\mathrm{B}]=1.12, P<.01)$, familiar predisposition $(\operatorname{Exp}$ $[\mathrm{B}]=0.64, P=.03$ ), and missing RCA bypass (Exp $[\mathrm{B}]=0.64, P=.04)$ are independent risk factors for impaired long-term outcome (Table E1). The results are summarized in Figure 4.

\section{DISCUSSION}

CTOs represent a technically challenging subset of coronary lesions that interventional cardiologists and cardiac surgeons face during revascularization. The prevalence of CTOs varies from $18 \%$ to $49 \%$ of all coronary angiograms, ${ }^{5,7}$ depending on the type of studied patients. A 
TABLE 4. Long-term follow-up: MACCE—overall and subgroup analysis "CABG only"

\begin{tabular}{|c|c|c|c|c|c|}
\hline & RCA-CABG & No-RCA-CABG & RCA, n & No-RCA, n & $P$ value \\
\hline MACCE overall & & & $\mathrm{n}=487(83.0 \%)$ & $\mathrm{n}=100(17.0 \%)$ & \\
\hline $\begin{array}{l}\text { Redo-CABG absolute no. } \\
(\%)\end{array}$ & $5(1.5)$ & $1(1.5)$ & 341 & 67 & $1.00^{*}$ \\
\hline \multicolumn{6}{|l|}{ Freedom of redo-CABG, mo } \\
\hline$\chi^{2}(\mathrm{df})$ & & & $0.50(1)$ & & $.48 \dagger$ \\
\hline $\begin{array}{l}\text { Postoperative PCI absolute } \\
\text { no. }(\%)\end{array}$ & $30(8.7)$ & $2(3.0)$ & 340 & 66 & $.14^{*}$ \\
\hline \multicolumn{6}{|l|}{ Freedom of PCI, mo } \\
\hline$\chi^{2}(\mathrm{df})$ & & & $0.27(1)$ & & $.60 \dagger$ \\
\hline $\begin{array}{l}\text { Myocardial infarction } \\
\text { absolute, } \mathrm{n}(\%)\end{array}$ & $32(9.3)$ & $4(6.2)$ & 341 & 64 & $.63 *$ \\
\hline \multicolumn{6}{|c|}{ Freedom of myocardial infarction, mo } \\
\hline$\chi^{2}(\mathrm{df})$ & & & $0.23(1)$ & & $.34 \dagger$ \\
\hline Stroke absolute no. $(\%)$ & $36(10.5)$ & $10(14.5)$ & 340 & 68 & $.333 \ddagger$ \\
\hline \multicolumn{6}{|l|}{ Freedom of stroke, mo } \\
\hline$\chi^{2}(\mathrm{df})$ & & & $0.47(1)$ & & $.50 \dagger$ \\
\hline $\begin{array}{l}\text { MACCE subgroup analysis, } \\
\text { "CABG only" }\end{array}$ & & & $\mathrm{n}=422(84.4 \%)$ & $\mathrm{n}=78(15.6 \%)$ & \\
\hline $\begin{array}{l}\text { Redo-CABG absolute no. } \\
\quad(\%)\end{array}$ & $5(1.7)$ & $1(1.9)$ & 296 & 52 & $1.00^{*}$ \\
\hline \multicolumn{6}{|l|}{ Freedom of redo-CABG, mo } \\
\hline$\chi^{2}(\mathrm{df})$ & & & $0.5(1)$ & & $.48 \dagger$ \\
\hline $\begin{array}{l}\text { Postoperative PCI absolute } \\
\text { no. }(\%)\end{array}$ & $25(8.4)$ & $2(3.8)$ & 295 & 51 & $.40^{*}$ \\
\hline \multicolumn{6}{|l|}{ Freedom of PCI in months } \\
\hline$\chi^{2}(\mathrm{df})$ & & & $0.27(1)$ & & $.60 \dagger$ \\
\hline $\begin{array}{l}\text { Myocardial infarction } \\
\text { absolute no. }(\%)\end{array}$ & $30(10.1)$ & $3(5.9)$ & 291 & 50 & $.45^{*}$ \\
\hline \multicolumn{6}{|c|}{ Freedom of myocardial infarction, mo } \\
\hline$\chi^{2}(\mathrm{df})$ & & & $0.00(1)$ & & $.99 \dagger$ \\
\hline Stroke absolute no. $(\%)$ & $27(9.1)$ & $6(11.3)$ & 295 & 52 & $.60_{\ddagger}^{\ddagger}$ \\
\hline \multicolumn{6}{|l|}{ Freedom of stroke, mo } \\
\hline$\chi^{2}(\mathrm{df})$ & & & $0.02(1)$ & & .88 \\
\hline
\end{tabular}

$R C A$, Right coronary artery; $C A B G$, coronary artery bypass grafting; $M A C C E$, major adverse cardiac and cerebrovascular events; $d f$, degrees of freedom; $P C I$, percutaneous coronary intervention. *Fisher exact test. $\nmid$ Log-rank test. $\ddagger \chi^{2}$ test.

relevant number of these patients are receiving IR. IR is more common in older patients presenting more frequently with relevant comorbidities such as previous stroke, renal impairment, and reduced ejection fraction. Also, urgent revascularization of patients with acute coronary syndrome shows a greater incidence of incomplete vessel grafting. ${ }^{12}$

A common reason for not revascularizing CTOs is the fear of causing a concurrent blood flow resulting in degradation of collaterals. However, a recent analysis showed that the Rentrop grade of collateralization is not associated with graft failure, ${ }^{4,7}$ and patients with high Rentrop gradings even showed a survival benefit as well as a lower incidence of MACCE when receiving revascularization by either CABG or PCI compared with medical treatment only. ${ }^{9}$ This is in line with our findings of a general survival benefit when revascularizing patients with CTO-RCA, since the majority of the patients in our cohort showed collateralization of the CTO vessel. However, we did not compare subgroups of different Rentrop grades.

Data suggest that a history of MI is present in $30 \%$ to $55 \%$ of the patients undergoing revascularization in the setting of $\mathrm{CTO},{ }^{8,13}$ which is in line with our findings of approximately $30 \%$ of patients with a history of MI. Nonetheless, the number of silent MIs is certainly underreported, since Q-wave electrocardiograms are only present in $25 \%$ of patients; however, $86 \%$ of these patients seem to have evidence of previous MI by late gadolinium enhancement. ${ }^{14}$ Even in the setting of acute ST-segment elevation myocardial infarction, the incidence of CTO is $13 \% .^{15}$ In this group, the presence of CTO in a non-infarct-related artery was found to be a strong and independent predictor for both early and late mortality. ${ }^{16}$ Most likely this effect is 

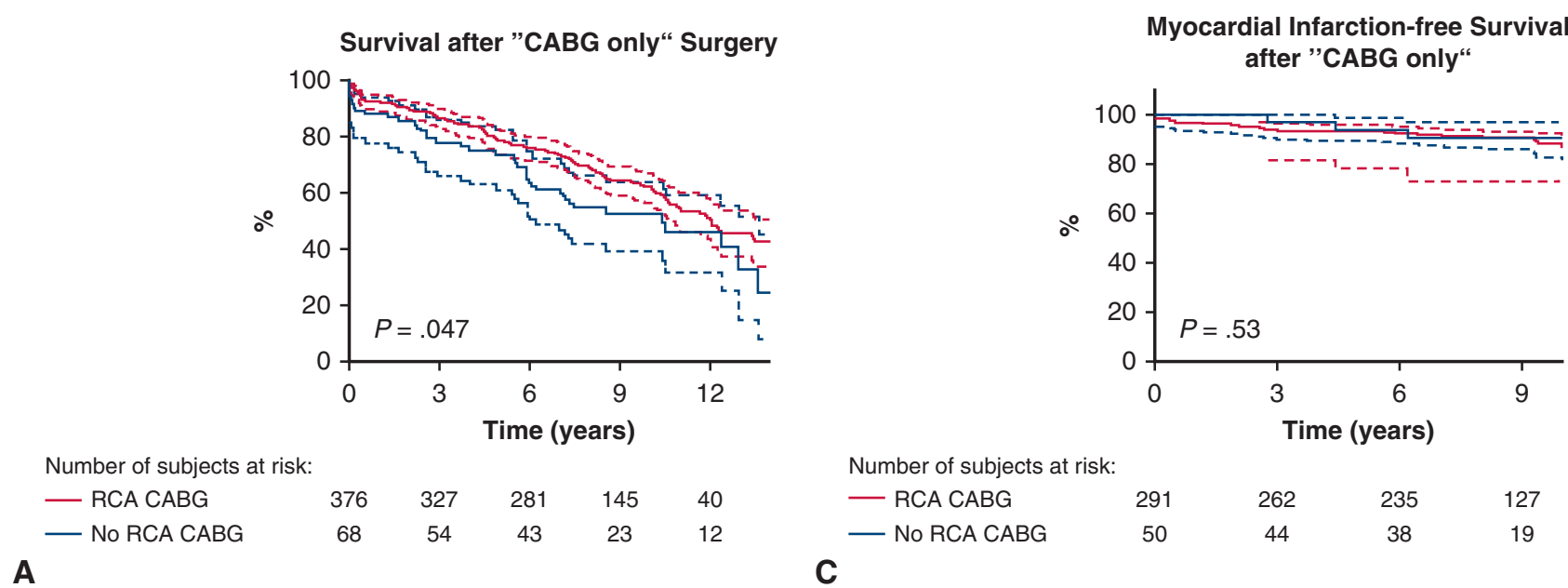

$\begin{array}{lccccc}\text { Number of subjects at risk: } & & & & & \\ \text { - RCA CABG } & 376 & 327 & 281 & 145 & 40 \\ \text { - No RCA CABG } & 68 & 54 & 43 & 23 & 12\end{array}$
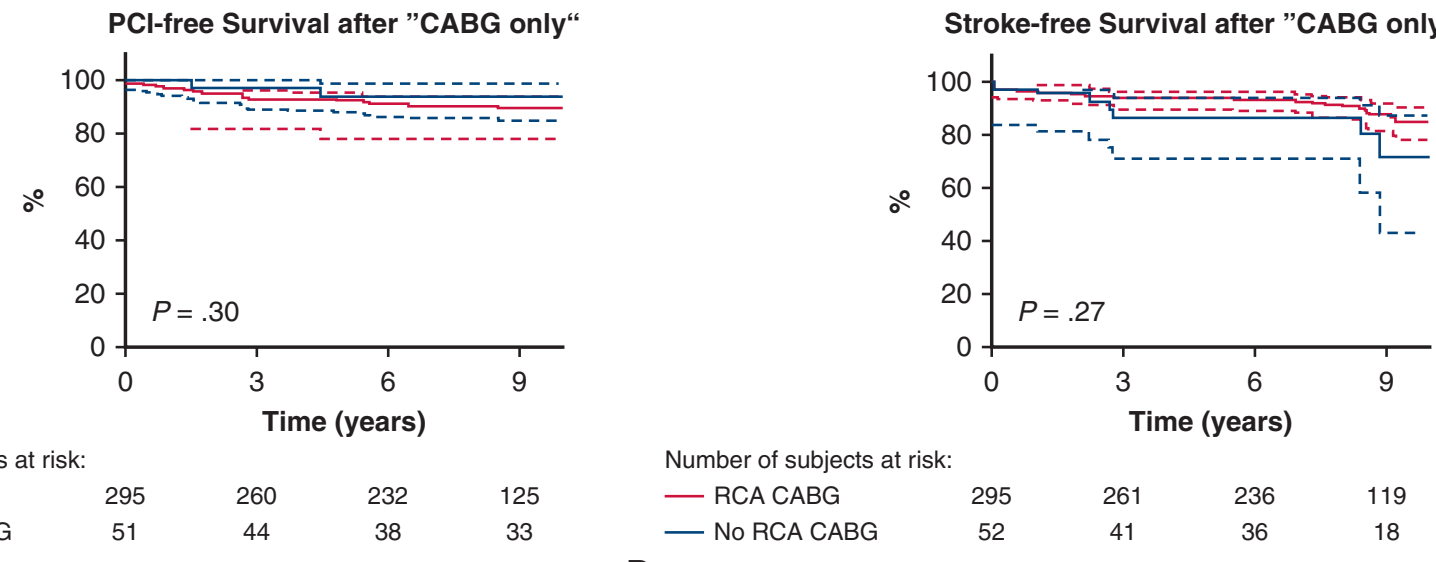

B

$\begin{array}{lcccc}\text { Number of subjects at risk: } & & & & \\ \text { - RCA CABG } & 295 & 260 & 232 & 125 \\ \text { - No RCA CABG } & 51 & 44 & 38 & 33\end{array}$

FIGURE 3. Log-rank analyses with $95 \%$ confidence limits in shadings. A, Subanalysis on survival after solitary CABG surgery. After excluding all patients who received additional surgical interventions, a survival benefit persists for patients who received surgical revascularization to chronic occluded RCAs as compared with patients who did not receive CABG grafting to chronic occluded RCAs $(P=.047)$. B, Subanalysis of PCI-free survival after solitary CABG surgery. No significant difference was detectable between patients who received CABG revascularization to chronic occluded RCAs and patients who did not receive revascularization $(P=.30)$. C, Subanalysis on myocardial infarction-free survival in patients after solitary CABG surgery comparing patients with and without CABG revascularization of chronically occluded RCAs. No significant difference between both cohorts was detectable $(P=.53)$. $\mathrm{D}$, Subgroup analysis on stroke-free survival in patients with chronically occluded RCAs who either received CABG grafting to the occluded RCA or not. No statistically significant difference between both groups was detectable $(P=.27)$. $C A B G$, Coronary artery bypass grafting; $R C A$, right coronary artery; $P C I$, percutaneous coronary intervention.

caused by the inability to provide collaterals to the occluded vessel combined with acute impairment of preexisting collaterals from the acutely occluded vessel to the CTO leading to a large myocardial territory at risk, this being a potential explanation for the prognostic benefit of treating CTOs. In interventional studies comparing successful PCI of CTOs with failed attempts, successful CTO revascularization resulted in a significantly improved 10-year survival $(73.5 \%$ vs $65 \%)$, whereas survival of successfully revascularized CTO patients was similar to revascularized nonCTO patients. ${ }^{13}$

In interventional studies comparing successful PCI of CTOs with failed attempts, CTO revascularization resulted in a significantly improved 1 -year outcome ( $3 \%$ vs $7 \%$ ) \% 1 -year mortality in nonattempted or failed CTO-PCI group, $P=.01 .^{17}$

Although CR is generally recommended in coronary revascularization, in many cases, especially in the presence of a CTO, revascularization is incomplete. ${ }^{3-6}$ There might be several reasons for not anastomosing a CTO, such as serve arteriosclerosis, small vessels, or good collateralization. Rentrop and colleagues ${ }^{18}$ defined an angiographic grading system based on retrograde filling of the occluded arterial segment. In particular, CTOs with a Rentrop grade 0 (no retrograde filling) seem to be poor candidates for successful revascularization, 
Outcome of Coronary artery bypass grafts to chronic occluded right coronary arteries
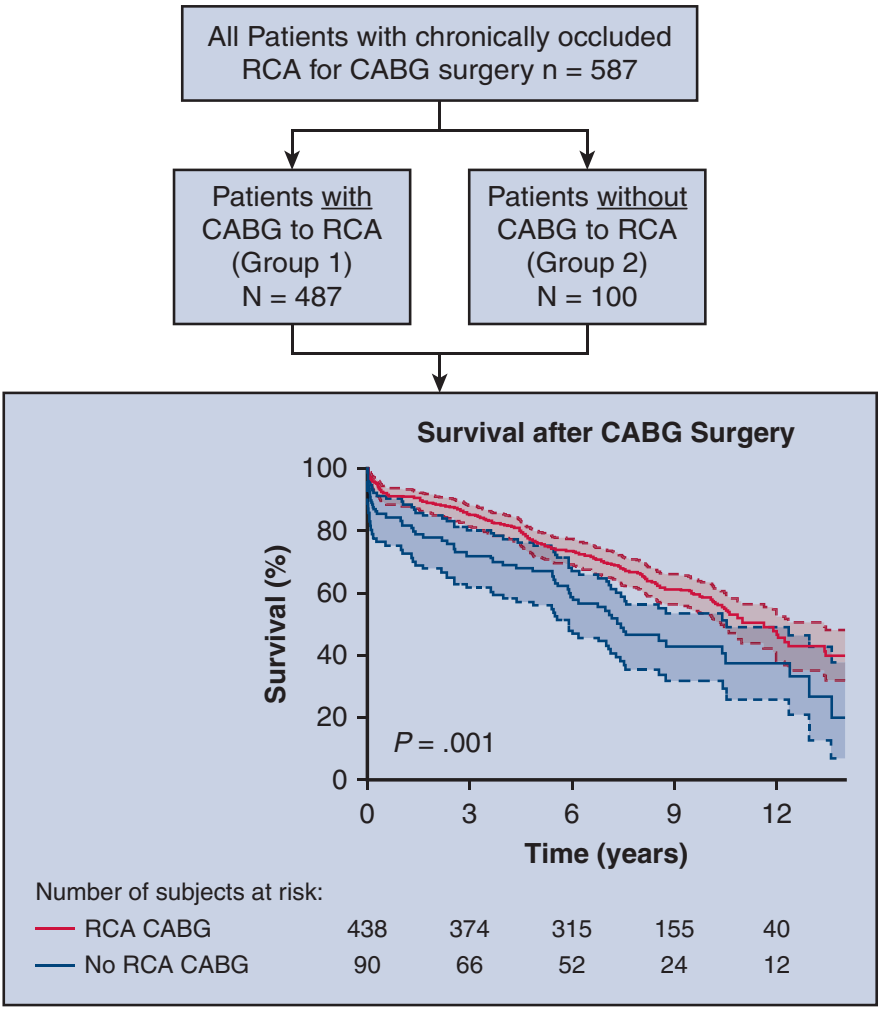

Retrospective analysis on revascularization of chronically occluded right coronary arteries during CABG surgery.

\section{Methods: \\ 587 patients undergoing CABG surgery with chronic occluded right coronary arteries.}

Group 1 received revascularization of the right coronary artery, Group 2 did not. Postoperative outcome including survival and MACCE events were recorded.

\section{Results:}

No statistical difference between both groups for: - stroke-free survival $(P=.05)$

- myocardial-infarction free survival $(P=.57)$ - PCl-free survival $(P=.17)$

Significant survival benefit in patients that received revascularization to the chronically occluded $\operatorname{RCA}(P=.001)$.

\section{Implications:}

Revascularization of chronic occluded right coronary arteries leads to a survival benefit in patients undergoing $C A B G$ surgery.

FIGURE 4. Patients with chronically occluded RCAs undergoing CABG were divided in 2 groups depending on whether the myocardium of the occluded RCA received surgical revascularization or not. A total of 587 patients were included, of whom 487 patients received a CABG to the RCA or its branches, whereas 100 patients with an occluded RCA did not receive surgical revascularization. No statistical difference between both groups was detectable in myocardial infarction-free survival $(P=.57)$, stroke-free survival $(P=.05)$, or PCI-free survival $(P=.17)$. However, survival analysis, as displayed in the Kaplan-Meier curve, revealed a better survival in patients with revascularization of the occluded RCA as compared with patients without revascularization $(P=.001)$, suggesting that surgical revascularization of an occluded RCA is recommended. $R C A$, Right coronary artery; $C A B G$, coronary artery bypass grafting; MACCE, major adverse cardiac and cerebrovascular events; $P C I$, percutaneous coronary intervention.

especially when the CTO is located in the territory of the RCA. Contrary to this, revascularization of a CTO in the left anterior descending or the left circumflex coronary artery does not depend on Rentrop grades. ${ }^{4}$ Hence, a common fear of revascularizing a CTO is that a competitive blood flow between the graft and the collateral vessel could lead to an early graft or collateral degradation resulting in increased myocardial ischemia. This is a common fear, although Oshima and colleagues ${ }^{7}$ and Gestrich and colleagues ${ }^{4}$ have shown that a high Rentrop grade is not associated with graft failure and Jang and colleagues ${ }^{9}$ demonstrated that even patients with a high Rentrop grade benefit from revascularizing CTO vessels. In addition, Allahwala and colleagues ${ }^{19}$ observed that successful revascularization is mostly dependent on the collateral filling of the occluded vessel.

At our institution, CR has been the primary goal in CABG. Yet, revascularization of CTO has been largely subject to surgeons' preference and choice, providing us with the necessary 2 different cohorts to make the herein reported comparison. Since in many cases, at our institution, the decision to graft a CTO-RCA or not was subjective and not led by strict medical criteria; the resulting 2 cohorts are remarkably similar in many preoperative variables and risk factors. In our study, CR including grafting the CTO-RCA shows a significantly improved long-term outcome with a remarkable survival benefit at all time points. This survival benefit persists in a subgroup analysis in patients who solely received a CABG procedure without any additional surgical interventions. Since confounding by other important variables is a common problem in retrospective analyses, we performed a Cox regression analysis for independent factors influencing the survival benefit and, other than grafting the CTO-RCA, found only 2 further independent survival predictors: family history of cardiovascular disease and greater EuroSCORES II. Interestingly, we did not detect significant differences concerning MACCE criteria during follow-up. This could be due to the fact that general risk factors were not different between the 2 groups, and coronary reintervention of the 
CTO-RCA, after it was decided that revascularization was not doable/necessary in the first place, was not attempted anymore later on.

\section{Limitations}

The study has the common limitations of retrospective data analyses, the most prominent limitation being the lack of angiography follow-ups to check on graft patency in the vast majority of patients. Also, the cause of death in our patients during follow-up could not be determined in the majority of patients.

\section{CONCLUSIONS}

CR of CTOs leads to improved long-term outcome. However, to find the underlying effect causing impaired survival in these patients, further studies have to be conducted. This study can serve as a basis for future prospective studies aiming on developing clear recommendations for cardiac surgeons how to deal with chronically occluded coronaries. Ideally, patients before CABG surgery should be included with preoperative diagnostics that include myocardial vitality assessment. Yet, the survival benefit found in our data set of RCA-CABG patients justifies the recommendation to make an effort to revascularize chronically totally occluded RCAs during coronary artery bypass grafting surgery whenever feasible.

\section{Conflict of Interest Statement}

The authors reported no conflicts of interest.

The Journal policy requires editors and reviewers to disclose conflicts of interest and to decline handling or reviewing manuscripts for which they may have a conflict of interest. The editors and reviewers of this article have no conflicts of interest.

\section{References}

1. Gershlick AH, Khan JN, Kelly DJ, Greenwood JP, Sasikaran T, Curzen N, et al Randomized trial of complete versus lesion-only revascularization in patients undergoing primary percutaneous coronary intervention for STEMI and multivessel disease: the CvLPRIT trial. J Am Coll Cardiol. 2015;65:963-72.

2. Bell MR, Gersh BJ, Schaff HV, Holmes DR Jr, Fisher LD, Alderman EL, et al. Effect of completeness of revascularization on long-term outcome of patients with three-vessel disease undergoing coronary artery bypass surgery. A report from the Coronary Artery Surgery Study (CASS) Registry. Circulation. 1992; 86:446-57.

3. Konstanty-Kalandyk J, Bartuś K, Piątek J, Kędziora A, Darocha T, Bryniarski KL, et al. Is right coronary artery chronic total vessel occlusion impacting the surgical revascularization results of patients with multivessel disease? A retrospective study. PeerJ. 2018;6:e4909.
4. Gestrich C, Lagemann D, Duerr GD, Konrad N, Sinning JM, Mellert F. Surgical revascularization of chronically occluded coronary arteries-what you see is what you get? Thorac Cardiovasc Surg. 2020;68:660-8.

5. Fefer P, Knudtson ML, Cheema AN, Galbraith PD, Osherov AB, Yalonetsky S, et al. Current perspectives on coronary chronic total occlusions: the Canadian Multicenter Chronic Total Occlusions Registry. J Am Coll Cardiol. 2012;59: 991-7.

6. Banerjee S, Master RG, Peltz M, Willis B, Mohammed A, Little BB, et al. Influence of chronic total occlusions on coronary artery bypass graft surgical outcomes. J Card Surg. 2012;27:662-7.

7. Oshima H, Tokuda Y, Araki Y, Ishii H, Murohara T, Ozaki Y, et al. Predictors of early graft failure after coronary artery bypass grafting for chronic total occlusion. Interact Cardiovasc Thorac Surg. 2016;23:142-9.

8. Deshmukh V, Phutane MV, Munde K, Bansal N. Clinical profile of patients with chronically occluded coronary arteries: a single center study. Cardiol Res. 2018; 9:279-83.

9. Jang WJ, Yang JH, Choi SH, Song YB, Hahn JY, Choi JH, et al. Long-term survival benefit of revascularization compared with medical therapy in patients with coronary chronic total occlusion and well-developed collateral circulation. JACC Cardiovasc Interv. 2015;8:271-9.

10. Widimsky P, Straka Z, Stros P, Jirasek K, Dvorak J, Votava J, et al. One-year coronary bypass graft patency: a randomized comparison between off-pump and onpump surgery angiographic results of the PRAGUE-4 trial. Circulation. 2004; 110:3418-23.

11. Nashef SA, Roques F, Sharples LD, Nilsson J, Smith C, Goldstone AR, et al. EuroSCORE II. Eur J Cardiothorac Surg. 2012;41:734-44; discussion 744-5.

12. Fefer P, Gannot S, Kochkina K, Maor E, Matetzky S, Raanani E, et al. Impact of coronary chronic total occlusions on long-term mortality in patients undergoing coronary artery bypass grafting. Interact Cardiovasc Thorac Surg. 2014;18: 713-6.

13. Suero JA, Marso SP, Jones PG, Laster SB, Huber KC, Giorgi LV, et al. Procedural outcomes and long-term survival among patients undergoing percutaneous coronary intervention of a chronic total occlusion in native coronary arteries: a 20year experience. J Am Coll Cardiol. 2001;38:409-14.

14. Choi JH, Chang SA, Choi JO, Song YB, Hahn JY, Choi SH, et al. Frequency of myocardial infarction and its relationship to angiographic collateral flow in territories supplied by chronically occluded coronary arteries. Circulation. 2013; 127:703-9.

15. Moreno R, Conde C, Perez-Vizcayno MJ, Villarreal S, Hernandez-Antolin R, Alfonso F, et al. Prognostic impact of a chronic occlusion in a noninfarct vessel in patients with acute myocardial infarction and multivessel disease undergoing primary percutaneous coronary intervention. J Invasive Cardiol. 2006;18:16-9.

16. Claessen BE, van der Schaaf RJ, Verouden NJ, Stegenga NK, Engstrom AE, Sjauw KD, et al. Evaluation of the effect of a concurrent chronic total occlusion on long-term mortality and left ventricular function in patients after primary percutaneous coronary intervention. JACC Cardiovasc Interv. 2009;2: 1128-34.

17. Nikolakopoulos I, Choi JW, Alaswad K, Khatri JJ, Krestyaninov O, Khelimskii D, et al. Equipment utilization in chronic total occlusion percutaneous coronary interventions: insights from the PROGRESS-CTO registry. Catheter Cardiovasc Interv. 2021;97:658-67.

18. Rentrop KP, Feit F, Sherman W, Thornton JC. Serial angiographic assessment of coronary artery obstruction and collateral flow in acute myocardial infarction. Report from the second Mount Sinai-New York University Reperfusion Trial. Circulation. 1989;80:1166-75.

19. Allahwala UK, Kott K, Bland A, Ward M, Bhindi R. Predictors and prognostic implications of well-matured coronary collateral circulation in patients with a chronic total occlusion (CTO). Int Heart J. 2020;61:223-30.

Key Words: coronary artery disease, chronic occluded coronary arteries, coronary artery bypass grafting, CABG 
TABLE E1. Cox regression for independent factors influencing the survival benefit

$95 \%$ CI

\begin{tabular}{lcccccc} 
& B & df & $\boldsymbol{P}$ value & Exp(B) & Lower limit & Upper limit \\
\hline EuroSCORE II & 0.10 & 1 & $<.001$ & 1.11 & 1.07 & 0.14 \\
Familiar predisposition & -0.45 & 1 & .03 & 0.64 & 0.43 & 0.96 \\
RCA-CABG & -0.45 & 1 & .04 & 0.64 & 0.41 & 0.98 \\
\hline
\end{tabular}

df, Degrees of freedom; $\operatorname{Exp}(B)$, hazard ratio; $C I$, confidence interval; EuroSCORE II, European System for Cardiac Operative Risk Evaluation; RCA, right coronary artery; $C A B G$, coronary artery bypass grafting. 